\title{
Del Quijote de Cervantes a la novela en el Caribe colombiano después de la modernidad
}

\author{
From Quijote by Cervantes to the novel of the Colombian \\ Caribbean after modernity
}

Luis Fernando López Noriega, educadorunicordoba@hotmail.com

Universidad de Córdoba, Colombia

\section{Resumen}

Este artículo pretende delinear una posible arqueología de las relecturas y reescrituras de la novela de Cervantes El ingenioso Hidalgo don Quijote de la Mancha, que los autores latinoamericanos configuraron después del fenómeno de la modernidad de las letras. Específicamente, se aborda a Germán Espinosa para analizar el caso del Caribe colombiano. Este objetivo se establece a partir del estudio de los procedimientos narrativos de apropiación y desenmascaramiento de los ejes simbólicos esenciales que ya aparecen dialogando en la obra cervantina: el ser discreto vs. el ser vulgar, y que en la novela de los autores del Caribe colombiano - Germán Espinosa en particular — se podrían definir como marcas discursivas que construyen a los personajes históricos que figuran en su novela Los cortejos del diablo (1982). Por tanto, bajo las conclusiones de la aplicación metodológica de un análisis del campo de producción artística del Caribe colombiano, se ofrecen aquí futuras líneas de investigación en el marco de los estudios culturales y literarios.

Palabras claves: Apropiación, Cervantes, desenmascaramiento, discreto, Quijote, vulgar.

\section{Abstract}

This article aims to outline a possible archeology of the re-readings and re-writings of Cervantes' novel El ingenioso Hidalgo don Quijote de la Mancha, that Latin American authors shaped after the phenomenon of modernity of letters. Specifically, the article focuses on Germán Espinosa in order to analyze the case of the Colombian Caribbean. This objective is established from the study of narrative procedures of appropriation and unmasking of the essential symbolic axes that already dialogue in Cervantes' work: being discreet vs. being vulgar. These axes in the novels of the authors of the Colombian Caribbean - German Espinosa in particular - could be defined as discursive markers that build the historical characters contained in his novel The Devil Processions (1982). Therefore, under the conclusions of the methodological application of a field analysis of artistic production of the Colombian Caribbean, future research agendas within the framework of cultural and literary studies are suggested.

Keywords: Appropriation, Cervantes, discreet, Quixote, unmasking, vulgar. 


\section{Introducción}

A partir del estudio del binomio: reglas de escritura y hábitos de lectura de una época determinada, es cierto que se puede llegar a entender la relación intrincada entre las marcas simbólicas de una sociedad y el devenir histórico que ella cursa, precisamente en sus formas de representación, de comportamientos y de conductas.

El interés y objetivo del presente escrito se enfoca en estudiar cómo en el Quijote se establece una modalidad de escritura que devela tanto normas preexistentes de manejo del lenguaje - llámese retórica - y concepciones teóricas del acto de contar historias a través de la creación estéticallámese poética-, como también normas de conducta que se ejemplifican en diversos personajes que resultan desenmascarados a partir de los discursos que pronuncian y las marcas que acentúan. Aquí se construyen, intercambian y socavan los dos símbolos que fundamentan todo el mecanismo narrativo de la obra de Cervantes: el ser discreto y ser el vulgar. Por último, se podría delinear una arqueología de la reapropiación que los escritores latinoamericanos hicieron de estos símbolos luego de las relecturas y reescritura de la obra de Cervantes después de la modernización de las letras en América Latina.

\section{Proceso metodológico}

Para llevar a cabo este estudio, según Bourdieu (1995), en su texto Las reglas del arte, se deben realizar tres operaciones sumamente importantes. La primera se circunscribió a una determinación y análisis de lo que es el campo literario y su grado de autonomía dentro del campo del poder. Este aspecto requirió considerar las formas en que el campo literario define los límites respecto del campo del poder. Esta operación se dirigió hacia la tarea de reconstruir una historia de las manifestaciones culturales y las posiciones que determinan las bases principales del campo literario. En el caso de la novela en Latinoamérica y en el Caribe colombiano, se está hablando de la tradición que antecede a los autores que se analizan aquí; es decir, de las principales aristas del campo de la novela en esta región y el "decurso del tiempo" que ha construido unos límites y unas reglas necesarias para entrar en dicho campo.

La segunda operación consistió en establecer internamente el grado de lo que Bourdieu (1995) llama situación de competencia por la legitimidad. Esto no es otra cosa que la tarea de definir las posiciones centrales dentro del campo de la novela en el Caribe colombiano, las posiciones más marginales que luchan por escalar niveles superiores y las leyes de funcionamiento y de transformación, que precisamente regulan esas luchas. Así, se reconstruyó una estructura del campo de la novela en el Caribe colombiano, y lo más importante, las dinámicas de entrada en él por parte de individuos o grupos que buscan ser reconocidos en este espacio.

Como tercera y última operación se realizó el análisis de las experiencias de vida de las trayectorias artísticas de los autores, incluyendo las formaciones en cuanto a las escuelas o los grupos que han hecho parte de los caminos recorridos, y que a ciencia cierta son los habitus de los ocupantes de estas posiciones; es decir, los sistemas de disposiciones que, al ser producto de una trayectoria social y de una posición dentro del campo literario, encuentran en esa posición una ocasión más o menos propicia para actualizarse.

\section{Desarrollo}

Las normas de conducta que circularon en forma de libros de enseñanza en la época de Cervantes, seguramente constituyeron pretextos concretos en varios actos de la creación del Quijote, pretextos que funcionaron como fundamento para configurar este juego narrativo que deja marcas discursivas 
claras para que el lector de esa época las devele y desmonte.

Un ejemplo de esas normas de conducta que circularon en forma de libros de enseñanza es el texto de Torquatto Accetto (2001), Da Dissimulacao Honesta (La disimulación honesta). En el libo se diferencia concretamente a la persona que "disimula" de aquella que "simula" en su manera de manejar el lenguaje en público. Al respecto, Accetto advierte: «Disimular (...) honestidad y decoro forzados (...) que da algún reposo a la verdad para demostrarla a su tiempo» (p. 18). Y más adelante, el mismo Accetto establece la clara distinción respecto de la "simulación" en lo atinente al manejo del lenguaje en público, es decir, en lo que tiene que ver con la retórica:

La disimulación es una profesión de la cual no se puede hacer carrera en el Senado ni en escuela de pensamiento, por cuanto si alguien usa la misma máscara todos los días sería más notado que cualquier otro por la curiosidad de todos, pues dos excelentes disimuladores que existan no hacen noticia alguna (p. 21).

Y en el apartado VIII, “Lo que es la disimulación”, Accetto (2001) define la esencia de estas dos palabras: «La disimulación es la habilidad de no hacer ver las cosas como son. Quien simula no es, y quien disimula es» (p. 27).

Ahora bien, en el Quijote de Cervantes, estas marcas, que en un principio circularon como simples normas de conducta social, ya están insertadas como verdaderos símbolos de reglas de escritura en el campo literario de aquella época. En el prólogo, Cervantes (2005) imprime estas marcas para develarlas y desenmascararlas: «Desocupado lector: sin juramento me podrás creer que quisiera que este libro, como hijo del entendimiento, fuera el más hermoso, el más gallardo y más discreto que pudiera imaginarse» (p. 7). Aquí Cervantes apela a la palabra "discreto" para decirle al lector que precisamente el texto que pone a su consideración "quisiera" que hiciera gala de honestidad y entendimiento. Pero obviamente esto no va a ser así, tal y como lo explica más adelante cuando recibe las enseñanzas propias de la simulación por parte de un amigo suyo que no recibe nombre en esta obra pero es quien le aconseja utilizar citas clásicas y hasta bíblicas para componer dicho prólogo, sin distinguirlas históricamente ni atribuirles la autoría que les corresponde:

Lo primero en que reparáis de los sonetos epigramas o elogios que os faltan para el principio, y que sean de personajes graves y de título, se puede remediar en que vos mismo toméis algún trabajo en hacerlos, y después los podéis bautizar y poner el nombre que quisiéredes, ahijándolos al Preste Juan de las Indias o al Emperador de Trapisonda (Cervantes, 2005, p. 10).

Este mecanismo de creación estética en la composición de los textos era igualmente utilizado por Lope de Vega, y parece ser todo un arte poético de la simulación lo que precisamente Cervantes le está develando al lector desde el inicio de su obra.

Más adelante, Cervantes intercambia, desenmascara estas dos categorías. La del discreto o disimulado, hombre letrado con conocimiento del manejo del lenguaje (que ya se había elevado a símbolo de una cultura de su tiempo); y la del vulgar, hombre sin cultura alguna y sin mesura, de maneras toscas y hablar destemplado. Este desenmascaramiento implica construir una simulación narrativa y escenográfica para el lector, de tal manera que el mismo narrador posteriormente la desmonte en el uso de un registro falsamente culto que comporta obviamente la mención de figuras y frases propias de la novela de caballería y en general de la forma discursiva del ámbito letrado que circuló en la época de Cervantes. Por ejemplo, en el capítulo XXXIV del Quijote, "Donde se cuenta 
la noticia que se tuvo de cómo se había de desencantar a la sin par Dulcinea del Toboso, que es una de las aventuras más famosas de este libro", cada uno de los sabios se enuncia a sí mismo, en un aparato teatral que los Duques crean para burlarse del Quijote y simular el proceso de desencantamiento de Dulcinea del Toboso:

Llegando pues el carro a igualar al puesto, se levantó de su alto asiento el viejo venerable y, puesto en pie, dando una gran voz dijo:

Yo soy el sabio Lirgandeo.

Y pasó el carro adelante, sin hablar más palabra. Tras este pasó otro carro de la misma manera con otro viejo entronizado el cual haciendo que el carro se detuviese, con voz no menos grave que el otro dijo:

Yo soy el sabio Alquife, el grande amigo de Urganda la Desconocida.

Y pasó adelante.

Luego, por el mismo continente, llegó otro carro, pero el que venía sentado en el trono no era viejo como los demás sino hombrón robusto y de mala catadura, el cual, al llegar, levantándose en pie como los otros, dijo con voz más ronca y más endiablada:

Yo soy Arcalaús el encantador enemigo mortal de Amadís de Gaula y de toda su parentela (Cervantes, 2005, pp. 820-821).

Asimismo, en el capítulo XXXV, "Donde se prosigue la noticia que tuvo don Quijote del desencanto de Dulcinea, con otros admirables sucesos”, se enuncia Merlín:

Yo soy Merlín, aquel que las historias dicen que tuve por mi padre al diablo - mentira autorizada de los tiempos - príncipe de la mágica y monarca y archivo de la ciencia zoroástrica, émulo a las edades y a los siglos que solapar pretenden las hazañas de los andantes bravos caballeros a quien yo tuve y tengo gran cariño (Cervantes, 2005, p. 823).

Para Cervantes, estos registros letrados o literarios son útiles en la medida en que precisamente ayudan en la creación narrativa que fundamenta todo aquel acto de simulación, y por tanto, los dos símbolos (discreto/vulgar) se encuentran representados y a la vez desenmascarados en este juego narrativo que los entrecruza, hasta tal punto que no se llega a saber quién es quién.

\section{Latinoamérica y el Caribe: apropiaciones y desenmascaramientos}

Llegados a este punto surge una pregunta importante: en el caso latinoamericano, ¿cómo se dio la apropiación y las asimilaciones de estos símbolos a partir de las sucesivas lecturas y reescrituras en el llamado Nuevo Mundo que construyeron una imagen del Quijote de Miguel de Cervantes Saavedra?

Si algo tenemos claro es que estos símbolos ya circulaban en la América colonial, hecho que se evidencia en las maneras de pensar de la cultura que arribó a este continente. Por ejemplo, Roberto Fernández Retamar (2005), encuentra un gran contraste entre la imagen del hombre caribe-caníbal - el incivilizado o vulgar - y la del «hombre americano que Colón ofrece en sus páginas: la del arauaco, a quien presenta como pacífico, manso, incluso temeroso y cobarde» (p. 38). Asimismo, menciona Retamar que: 
El arauaco se transformará en el habitante paradisíaco de un mundo utópico: ya en 1516, Tomás Moro publica su Utopía; mientras que el Caribe, por su parte, dará el caníbal, el antropófago, el hombre bestial situado irremediablemente al margen de la civilización, y a quien es menester combatir a sangre y fuego (p. 14).

También es cierto que estas visiones, estas ideas, vehiculadas a través de esos símbolos, se continuaron manifestando en el tiempo. De hecho, como indica Retamar (2005), se constituyeron en el «arsenal ideológico de la enérgica burguesía naciente» (p. 38) en el siglo XIX.

Esta escritura-lectura decimonónica, este canon, tuvo en el caso colombiano sus continuidades y rupturas en las formas de construir, a partir de la escritura de la historia, lo que Alfonso Múnera (2005), llama «la geografía humana de la nación hasta sus elaboraciones más recientes en la primera mitad del siglo XX» (p. 34). A propósito, afirma Múnera:

De Caldas a José María Samper hay continuidad y ruptura. Ambos concibieron la geografía humana de la nación como escindida en dos grandes territorios: los Andes, habitados por las razas más civilizadas y superiores, y las costas, las tierras ardientes, las selvas, los grandes llanos, habitados por las razas incivilizadas e inferiores (p. 34).

Así, los territorios ya tenían sus imaginarios, sean impuestos o creados in situ.

Esta es una línea de investigación que buscaría la arqueología de las sucesivas lecturas que se le hicieron al Quijote, algunas más que otras imbuidas de contenidos ideológicos y políticos que servían para la construcción de los Estados-Nación. Por ejemplo, en el caso de la novela colombiana se ejerció de igual manera una lectura y apropiación de estos símbolos que buscaba la construcción escindida en las formas de evaluar el espacio-tiempo de los territorios de la nación. Se concebía la manifestación literaria como un instrumento de la "civilización" Occidental, como un vehículo sociológico usado por el hombre de "centro", de los Andes, para domesticar, instruir al caníbal, al Caribe, al incivilizado e inferior.

Por lo tanto, para la escritura ficcional de las novelas, la escritura novelística era un objeto susceptible de expresarse como el logro posible de una elaboración civilizada o del individuo cognoscente. De aquí surgen los modelos de "nación", y el espacio-tiempo fue utilizado para la definición homogénea y abarcadora de esta base ideológica. En ese sentido se expresa Lotman, citado por Zubiaurre (2002), al señalar que: «Los modelos históricos y lingüísticos nacionales del espacio se convierten en la base organizadora para la construcción de una 〈imagen del mundo〉, un modelo ideológico global propio de un tipo de cultura dado» (p. 272).

Ahora, otra pregunta importante que emerge es, ¿a través de qué mediaciones, es decir, a través de cuáles otros autores que influenciados por la lectura y las técnicas narrativas expuestas por Cervantes en el Quijote, llegaron a construirse estos símbolos de los que hablamos en el caso latinoamericano?

En efecto, se sabe que Shakespeare, por ejemplo, leyó el Quijote. Pero, ¿hasta qué punto Cervantes fue importante para la escritura de La tempestad (2007)? Es un cuestionamiento esencial por cuanto es en esta obra donde aparece el símbolo del Calibán como el incivilizado y vulgar, en un juego de palabras que proviene del caníbal. 


\section{Conclusiones en forma de líneas de investigación para el futuro}

Una línea de investigación esencial comportaría precisamente estas asimilaciones, estas reapropiaciones del Quijote, pero en el tiempo de los escritores ubicados después de la llamada modernización de las letras latinoamericanas, y en especial, en la escritura de la nueva novela histórica. Es el caso, por ejemplo, del colombiano Germán Espinosa (1970), con su obra Los cortejos del diablo.

Para dilucidar estos cuestionamientos habría que echar mano del aparato teórico de la literatura comparada y del análisis del discurso, así como también de las diferentes marcas históricas que podrían rastrearse en el campo de la escritura literaria en Colombia en el contexto de los autores pertenecientes a la generación posterior a Gabriel García Márquez.

A partir de allí se instalaría una primera dificultad principal para el desarrollo de una posible línea de investigación, toda vez que estaría constituida por el hecho de tratar de articular a estos fenómenos de permanente evaluación, reapropiación, desenmascaramientos narrativos y de reflexión sobre la memoria histórica de las ciudades en el Caribe colombiano, unos constructos teóricos que si bien ofrecen explicaciones sustentadas en la tradición Occidental, para nuestro caso habría que ampliar y evaluar si resultan de eficacia. Por ejemplo, el concepto de heterotopía (Foucault, 2010) permite emprender la reflexión acerca de los espacios y tiempos de la memoria ficcionalizada, de un Caribe distinto al que aparece construido en la norma de escritura literaria instaurada por la figura de Gabriel García Márquez.

Otra dificultad sería la reflexión sobre la tríada memoria histórica-territorio-escritura ficcional, desde la perspectiva del concepto de reconocimiento y desde los fenómenos de reificación del campo de producción cultural en el Caribe colombiano a partir de la modernización de las letras latinoamericanas.

Sólo así se podría llegar a establecer algunas conjeturas y muchas más dudas.

\section{Referencias}

Accetto, T. (2001). Da Dissimulacao Honesta. Sao Paulo: Martins Fontes.

Bourdieu, P. (1995). Las reglas del arte. Barcelona: Anagrama.

Cervantes, M. (2005). El ingenioso hidalgo don Quijote de la Mancha. Madrid: Real Academia de la Lengua.

Espinosa, G. (1970). Los cortejos del diablo. Bogotá: Altamir

Foucault, M. (2010). El Cuerpo Utópico, Las Heterotopías. Buenos Aires: Ediciones Nueva Visión.

Múnera, A. (2005). Las fronteras imaginarias. Bogotá: Planeta.

Retamar, R. (2005). Todo Calibán. Bogotá: Instituto de altos estudios jurídicos.

Shakespeare, W. (2007). La tempestad. Madrid: Cátedra.

Zubiaurre, M. T. (2002). El espacio en la novela realista. México: Fondo de Cultura Económica. 